\title{
Special investigations in COCM: Biochemical analysis of cardiac biopsies
}

\author{
ALF TORP \\ M.D. \\ Departments of Internal Medicine and Clinical Physiology, University of Lund, \\ Malmö General Hospital, S-214 01 Malmö, Sweden
}

\begin{abstract}
Summary
The introduction of the endomyocardial biopsy method has permitted unique possibilities to investigate the myocardium. Compared to several other methods described, it is superior for taking serial biopsies on one or more occasions. With already available methods, examination of heart muscle biopsies can be extended to a wide variety of biochemical analyses. The ultimate application of repeated or periodic tissue sampling is the potential of combining static and dynamic studies.
\end{abstract}

\section{Introduction}

The chemical composition and metabolism of the myocardium has been quite extensively studied during the last decades, both in normal and diseased hearts and after certain experimental manoeuvres, such as sudden increase in afterload or exposition to different agents. These studies in man have usually been limited to the use of indirect methods, such as blood sampling from the coronary sinus or measuring the cardiac performance after certain actions. Experimental studies in animals have given much valuable information but these findings have only a limited application to man. Experience with human, vital myocardial tissue is very limited, chiefly owing to the lack of acceptable biopsy methods. Tissue specimens obtained at surgery are, for obvious reasons, not quite representative when analysing physiological functions, e.g. anaesthesia and the non-physiological situation in general may constitute too many sources of error. Transthoracic needle biopsy gives a very small tissue sample, making microscopical findings difficult to interpret owing to the presence of artefacts (Eckner et al., 1967). Besides, this method carries a high frequency of complications. In a recent report serious complications occurred in about $7 \%$ of the investigated 198 cases (Shirey et al., 1972).

The endomyocardial biopsy method introduced by Konno and Sakakibara (1963) has now been widely accepted. Numerous reports from different centres have confirmed the reliability and safety of the method (Somers et al., 1971; Torp, 1973; Ali et al., 1973; Mackay, Littler and Sleight, 1974; Hirota, Khaja and Abelmann, 1976; Petitier et al., 1976; Hess et al., 1977). The procedure yields a tissue specimen, consisting almost entirely of myocardium and weighing about $5 \mathrm{mg}$. In addition, the biopsy can be repeated on the same or several occasions without any obvious discomfort to the patient. Complications of significance have not been reported so far. Some modifications of the method have been reported (Richardson, 1974; Caves et al., 1974), their main advantage is that the instrument has a smaller diameter, permitting percutaneous introduction in arteries and veins. This makes biopsy from the left ventricle very much easier than with the original method.

Knowledge of diseases in various organs have advanced rapidly after the introduction of simple biopsy methods permitting the correlation of the pathological features with the clinical and metabolic manifestations. Cardiac biopsy has not previously been supported by much enthusiasm, which reflects the relative lack of knowledge of the metabolic and biochemical behaviour of the human myocardium. Nowadays, this attitude has changed, and one can expect valuable information rapidly to accumulate. The tissue samples obtained using endomyocardial biopsy have proved to be of sufficient size for application of conventional chemical methods. For instance, it is possible to assay a large number of enzymes, marking different intracellullar organelles (Peters, 1977). The results show certain alterations in the activity of some enzymes in patients with congestive cardiomyopathy and left heart failure, suggesting abnormalities in mitochondrial function. The results have not yet permitted any definite conclusions but further work is certainly essential, as similar methods have been of great value in the investigation of diseases of, e.g. the liver and intestine. The electron-microscope now permits mitochondria clearly to be seen in cardiac biopsies, which helps to establish the correlation between structural and biochemical changes. 


\section{Methods and results}

Some years ago, glucagon was popular in the treatment of heart failure. To evaluate the possible effect and mode of action of this substance, a longacting preparation of the drug, protamine-zincglucagon (kindly supplied by NOVO industries), was given to seven patients. The group consisted of patients with cardiomyopathy in heart failure as well as patients with other forms of heart disease with a fairly normal blood picture. All cases underwent complete right and left heart catheterization at rest and during exercise using routine methods (Torp, 1978). After exercise, a biopsy was taken from the apical part of the right ventricle; $20 \mathrm{mg}$ of the drug was then given intramuscularly and allowed to act for $\mathbf{4 5}$ minutes, after which the whole procedure, including biopsy, was repeated. The tissue samples were frozen at $-70^{\circ} \mathrm{C}$ and stored until simultaneous analysis was made. Using a sensitive radioimmunoassay (Frandsen and Torp, 1978), the tissue concentration of cyclic AMP in the two biopsies in each case was determined.

The haemodynamic data from the patients suggested that the drug had had some positive effect on the heart performance. The filling pressure of the left ventricle, expressed as the mean pulmonary artery wedge pressure (Fig. 1a), decreased, cardiac index (Fig. 1b) and stroke index (Fig. 1c) increased slightly at rest. The reaction of brachial artery mean pressure and heart rate is illustrated in Fig. 1d and e. When plotting the mean values for the haemodynamic parameters against the plasma concentration of glucagon (Fig. 2a and b). it can be seen that the changes in haemodynamics coincide with an increase in glucagon concentration. This increase,

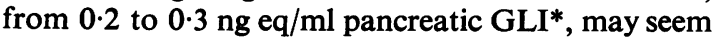
slight, but is nevertheless highly significant (Heding, personal communication, 1972). The figures for the tissue concentration of cyclic AMP (Table 1) show that the individual values within the group of patients correspond quite well. There is no significant increase in the concentration of cyclic AMP after administration of glucagon in a dose causing haemodynamic effects. The aim of the study was to investigate the effect of glucagon upon the cyclic AMP-adenyl cyclase system, but the results did not support earlier work, indicating that the beneficial effect of the hormone on heart performance is mediated through the activation of adenyl cyclase (Gold et al., 1970). Without penetrating any further into the mode of action of glucagon, it can also be noted, that the same lack of increase of cyclic AMP was present in all the seven patients, regardless of their degree of heart failure. Other, more recent investigations (Wildenthal et al., 1976) have come

\footnotetext{
*glucagon-like immunoreactivity.
}

to the same conclusion, although this work was done using fetal hearts from animals.

Despite the fact that this investigation did not give any further information about the cellullar action of glucagon, it illustrates a possible procedure for the examination of cardioactive drugs. Also, it illustrates that biochemical methods, if sensitive enough, can be applied to relatively small biopsy samples. In this study, the size of the samples averaged $5 \mathrm{mg}$. The prerequisite is, however, the possibility of obtaining repeated cardiac biopsies. A better understanding of the pathogenesis of cardiomyopathies requires, among other information a classification on a biochemical basis. Until now, the principle of dividing the disease into different forms is based on clinical features, haemodynamic data and pathological findings. It may, however, be possible that the same pathogen provokes different reactions of the myocardium in different individuals, leading to varying forms of heart muscle disease.

The effect of alcohol on the heart has been quite extensively studied, chiefly haemodynamically, but even different pathological changes have been demonstrated in animals and in man (Mitchell and Cohen, 1970). To the best of the author's knowledge, biochemical studies of the influence of alcohol on human myocardium have not so far been undertaken. Some experimental data have suggested that the ingestion of alcohol by animals leads to an accumulation of triglycerides in the myocardium (Alexander et al., 1977). In an experimental study in the dog, a dose-related increase in triglyceride concentration in myocardial tissue was demonstrated during infusion of ethanol (Wong, 1974). The increase occurred as early as $\mathbf{1 5} \mathrm{min}$ after the start of the infusion. The triglyceride concentration was uniform within and between ventricles and endocardium, which justified the use of serial biopsies from the right ventricle for tissue sampling. Haemodynamically, a decrease of left ventricular performance occurred within $15 \mathrm{~min}$. This temporal coincidence with the lipid accumulation suggests a cause-and-effect relationship.

In an attempt to reproduce these findings in man, the concentration of phospholipids and triglycerides in myocardial biopsies was measured. Biopsies were taken from four patients with cardiomyopathy undergoing routine heart catheterization. As a control, one average and one large-size biopsy were taken from each of a number of post-mortem cases. All specimens were analysed simultaneously using gas chromatography after removal of visible fat and connective tissue under a stereo microscope. The preliminary results (Belfrage et al., 1978) show a very good correlation between the two samples from post-mortem material. The individual values of triglyceride in the biopsies from the live patients 

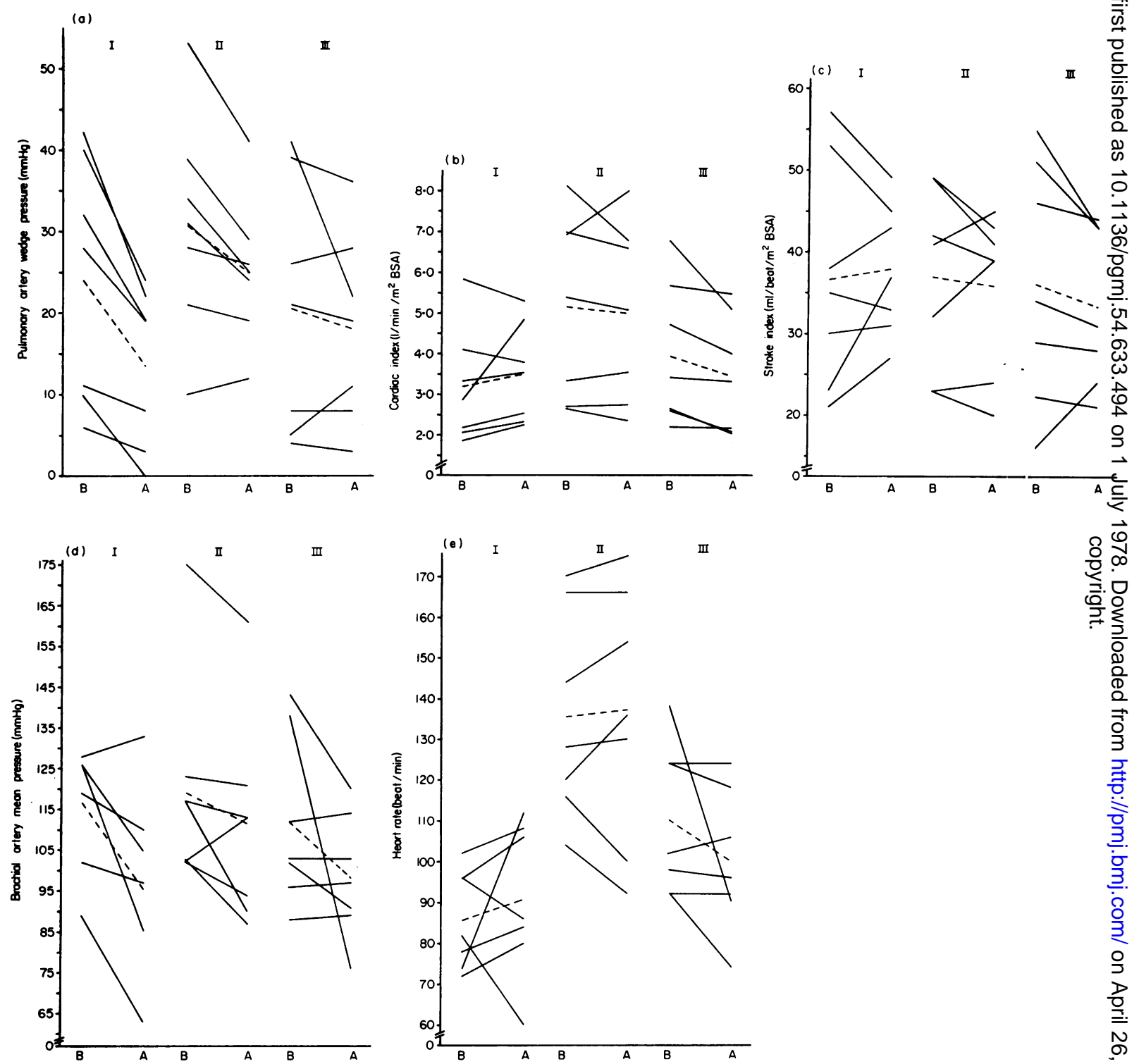

FIG. 1. (a) Individual values for differences in pulmonary artery wedge pressure before (B) and after (A) glucagon at rest (I); during exercise (II) and after exercise (III). Dotted lines indicate mean values.
(b) Indvidual values for cardiac index.
(c) Individual values for stroke index.
(d) Individual values for brachial artery mean pressure.
(e) Indvidual values for heart rate.

BSA = body surface area. 
(a)
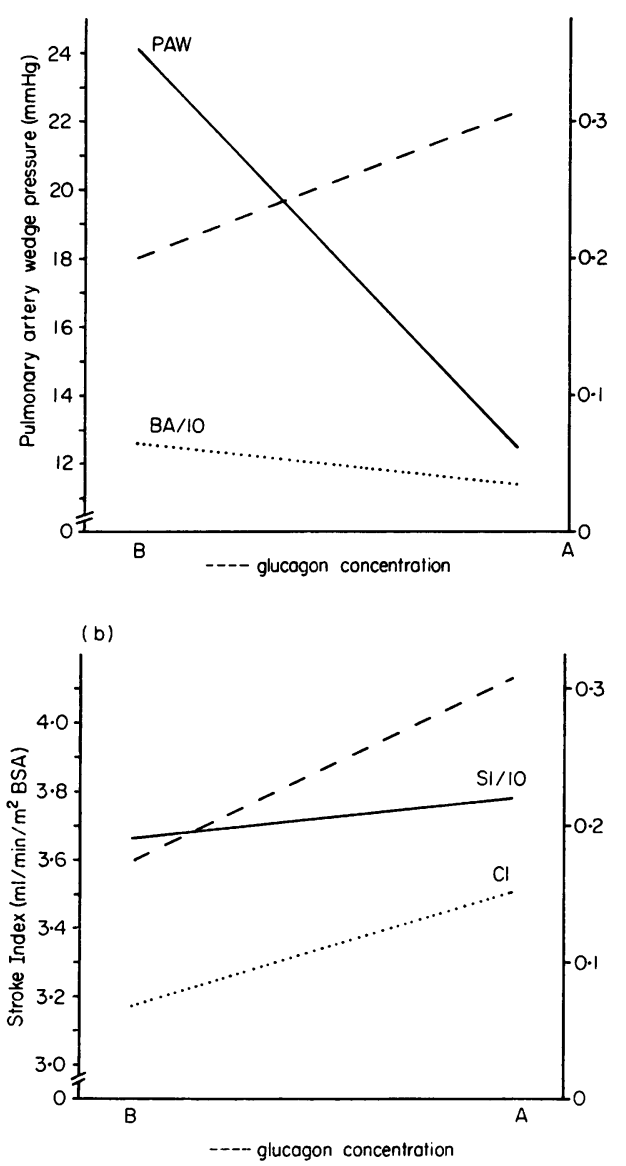

FIG. 2. (a) Differences in pulmonary artery wedge pressure (PAW) and brachial artery mean pressure (BA) before and after glucagon; plotted against plasma concentration of glucagon; expressed to the right in ng eq/ml pancreatic GLI.

(b) Differences in cardiac index (CI) and stroke index (SI).

showed, on the other hand, a rather wide variation (Table 2). The aim of this study, which is still in progress, is to investigate a number of alcohol addicts during a phase of acute abuse and after treatment in hospital. The individual variation in triglyceride concentration seems to require, that each patient is his own control. In the author's opinion, it is possible that either an abuse of alcohol, or an increased sensitivity of the myocardium to ethanol or its metabolites could be an aetiological factor in a large number of cases. So far, it has not been possible to demonstrate any pathognomonic changes in the myocardium secondary to alcohol compared to those in other forms of cardiomyo-
TABLE 1. Concentration of cyclic AMP before (B) and after (A) glucagon expressed in $\mathrm{pmol} / \mathrm{mg}$ tissue \pm s.e.mean

\begin{tabular}{ccc}
\hline & B & A \\
\hline 1 & $0.78 \pm 0.06$ & $0.89 \pm 0.13$ \\
2 & $0.51 \pm .003$ & $0.73 \pm 0.11$ \\
3 & $0.96 \pm 0.21$ & $1.05 \pm 0.22$ \\
4 & $0.99 \pm 0.08$ & $0.53 \pm 0.02$ \\
5 & $0.82 \pm 0.12$ & $0.79 \pm 0.12$ \\
6 & $1.33 \pm 0.13$ & $0.87 \pm 0.08$ \\
7 & $0.82 \pm 0.04$ & $0.95 \pm 0.03$ \\
\hline
\end{tabular}

TABLE 2. Triglyceride (TG) and phospholipid (PL) concentrations expressed in $\mathrm{nmol} / \mathrm{mg}$ wet weight of biopsy samples

\begin{tabular}{ccccc}
\hline $\begin{array}{c}\text { Patient } \\
\text { no. }\end{array}$ & $\begin{array}{c}\text { Wet weight } \\
\text { (mg) }\end{array}$ & TG & PL & TG/PL \\
\hline 1 & 1.5 & 2.8 & 43 & 0.062 \\
2 & 1.5 & 0.8 & 40 & 0.023 \\
3 & 2.2 & 3.5 & 47 & 0.078 \\
4 & 3.7 & 5.0 & 40 & 0.119 \\
\hline
\end{tabular}

pathies. It seems unlikely that the physical presence of lipids, which cannot be demonstrated by light or electron microscopy, can cause measurable decrease of heart function. Alternatively, it is theoretically possible that changes in the normal lipid concentration can give rise to changes in membrane function.

Using cardiac biopsy, the presence and distribution of foreign substances within the myocardium can be demonstrated. In a study of eight patients, $1.5 \mathrm{mCi}$ of ${ }^{201} \mathrm{Tl}$ was injected intravenously in connection with a routine investigation. A blood sample and a biopsy from the right ventricle were obtained simultaneously. After immersion in neutral formalin, the activity of ${ }^{201} \mathrm{Tl}$ in the tissue sample and the blood was measured using a gammaspectrometer. Shortly summarizing, the results (Mattsson et al., 1978) showed an average activity in the tissue samples of $250 \mathrm{nCi} / \mathrm{g}$, or $0 \cdot 25 \mathrm{nCi}$ per sample as the average wet weight was about $1 \mathrm{mg}$. The ratio of the activity between myocardium and blood was $25: 1$. Even though the activity of injected radioactive thallium not has been quantified in the myocardium before, it was an unexpected finding that only $4 \%$ of the label was present in the heart $30 \mathrm{~min}$ after the injection.

\section{Acknowledgments}

This work was supported by a grant from the Swedish National Association for Heart and Chest diseases. The determination of glucagon concentration was kindly performed by Dr Lise Heding; NOVO Research Laboratories. 


\section{References}

Alexander, C.S., Forsyth, G.W., Nagasawa, H.T. \& KOHLOFF, J.G. (1977) Alcoholic cardiomyopathy in mice. Myocardial glycogen, lipids and certain enzymes. Journal of Molecular and Cellular Cardiology, 9, 235.

Ali, N., Ferrans, V.J., Roberts, W.C. \& Massumi, R.A. (1973) Clinical evaluation of transvenous catheter technique for endomyocardial biopsy. Chest, 63, 399.

Belfrage, P., Johansson, B.W., TORP, A. \& Åkesson, B. (1978) Micromethods for analysis of lipids in endomyocardial biopsy specimens. (To be published.)

Caves, P.K., Stinson, E.B., Billingham, M.E. \& ShumWAY, N.E. (1974) Serial transvenous biopsy of the transplanted human heart. Lancet, i, 7862.

ECKNer, F.A.O., ThaemerT, J.C., Moulder, P.W. \& BLACKSTONE, E.H. (1967) Myocardial biopsy in dogs. Circulation, 36, 964.

FrandSen, E.K. \& TorP, A. (1978) Effect of glucagon on myocardial concentration of cyclic AMP. (To be published.)

Gold, H.K., Prindle, K.H., Levey, G.S. \& Epstein, S.E. (1970) Effects of experimental heart failure on the capacity of glucagon to augment myocardial contractility and activate adenyl cyclase. Journal of Clinical Investigation, 49, 999.

Hess, O.M., Schneider, J., Turina, M., Heeb, S., Grop, P. \& KRAYENBÜHL, H.P. (1977) Die transvenöse Endomyokardbiopsie in der Beurteilung der kongestiven Kardiomyopathie. Schweizerische Medizinische Wochenscrift, $107,293$.

Hirota, Y., Khaja, F. \& Abelmann, W.H. (1976) Effectiveness and hazard of endomyocardial biopsy in dogs: Comparison of two methods. American Heart Journal, 92, 767.

Konno, S. \& SaKakibara, S. (1963) Endomyocardial biopsy. Diseases of the Chest, 44, 345.
Mackay, E.H., LitTler, W.A. \& Sleight, P. (1974) Assessment of value of catheter biopsy of the heart. British Heart Journal, 36, 404.

Mattsson, S., Hansen, F., Lilja, B., Pettersson, C. \& TORP, A. (1978) Measurement of ${ }^{201} \mathrm{Tl}$-concentration in myocardial biopsies from patients with cardiomyopathy and other forms of heart disease. Nuclear Medicine, 17, 76.

Mitchell, J.H. \& COHEN, L.S. (1970) Alcohol and the heart. Modern Concepts of Cardiovascular Disease, 34, 109.

Peters, T.J. (1977) Application of analytical subcellular fractionation techniques and tissue enzymic analysis to the study of human pathology. Clinical Science and Molecular Medicine, 53, 505.

Petitier, H., Bouhour, J.B., Lajartre, A.Y.de, Crochet, D., Nicolas, G. \& HoreaU, J. (1976) La biopsie endomyocardique, innocuité et intérêt clinique. Archives des maladies du coeur, des vaisseaux et du sang, 69, 1005.

Richardson, P.J. (1974) King's endomyocardial bioptome. Lancet, $\mathrm{i}, 660$.

Shirey, E.K., Hawk, W.A., MukerJi, D. \& Effler, D.B. (1972) Percutaneous myocardial biopsy of the left ventricle. Circulation, 46, 112.

Somers, K., Hutt, M.S.R., Patel, A.K. \& D'Arbela, P.G. (1971) Endomyocardial biopsy in diagnosis of cardiomyopathies. British Heart Journal, 33, 822.

TORP, A. (1973) Endomyocardial biopsy. Scandinavian Journal of Thoracic and Cardiovascular Surgery, 7, 253.

TORP, A. (1978) Hemodynamic effects of long-acting glucagon. (To be published.)

Wildenthal, K., Allen, D.O., Karlsson, J., Wakeland, J.R. \& ClARK, C.M. (1976) Responsiveness to glucagon in fetal hearts. Journal of Clinical Investigation, 57, 551.

WoNG, M. (1974) In vivo sampling of cardiac triglyceride from dogs using ethanol infusion. Journal of Lipid Research, 15, 50. 